\title{
IT TAKES WORK: HOW MICRO-PROCESSES OF SOCIALISATION CONSTRUCT NEWCOMERS' DENTIFICATION IN TEAMS
}

\author{
EMMA PERRITON \\ Department of Management \\ Aarhus University \\ 8210 Aarhus V
}

INTRODUCTION

\begin{abstract}
While all organisations face socialisation of their newcomers, they too increasingly must ensure that individuals come to identify with the work team they belong to. In the abundance of literature on identification, however, not much attention is given to how identification develops during socialisation, despite most often being the starting point of identification with a given working unit. In particular, understanding processes of informal socialisation, including how socialisation agents and the relationship between newcomers and peers influence newcomers' identification and socialisation process is underexplored and underestimated in current research (Ashforth \& Saks, 1996; Feldman, 1994; Korte, 2009; Sluss, Ployhart, Cobb, \& Ashforth, 2012; Smith, Amiot, Callan, Terry, \& Smith, 2012). Yet, we cannot neglect such significant others in a newcomer's working unit in the socialisation process, since identifying and becoming part of a group is "both something we do to ourselves and something we do to each other" (Wenger, 1998: 191). Also overlooked in existing research is approaching identification and socialisation from a process perspective (Ashforth, Harrison, \& Corley, 2008; Langley, Smallman, Tsoukas, $\&$ Van de Ven, 2013). Adding to that, although it is recognised that it is through practices that we become members of a community such as a work team (Lave \& Wenger, 1991; Wenger, 1998), most emphasis has been put on the community, and not as much on the practices involved (Duguid, 2005), and thereby the work members actually engage in. This study addresses the abovementioned issues by asking how do micro-processes of socialisation construct newcomers' identification in teams? Through a two-and-a-half-year longitudinal ethnography of two teams from knowledge-intensive organisations, I explore how newcomers are socialised in teams. I find that newcomers engaged in 'identification work' fostering team identification, whilst existing team members engaged in what I term 'socialisation work'; behaviours that either encouraged or discouraged newcomers' process of socialisation and in that also identification. Finally, members' negotiated norms and values determined how newcomers came to be accepted as full team members. Collectively, these micro-processes of socialisation came to construct newcomers' identification with their team. By unpacking how identification is constructed during socialisation, I develop socialisation theory with the conceptualising of identification work, socialisation work and acceptance mechanisms as collective micro-processes of socialisation. With this study, I therefore extend theory within and between the fields of identification and socialisation.
\end{abstract}

\section{IDENTIFICATION AND SOCIALISATION PROCESSES}

By way of identification, we navigate our surroundings; it is how we make sense of (organisational) life (Ashforth et al., 2008). Thus, identification remains an everlasting topic for organisations and organisational scholars (Ashforth, 1998; Haslam \& Ellemers, 2011). Of interest here is team identification (also referred to as group identification), a form of social 
identification reflecting group membership. Since Ashforth and Mael's favoured definition of social identification as "the perception of oneness with or belongingness to a group" (1989, p. 34 ), and the once stable and somewhat linear view on identification, current work now acknowledges identification as a relational process (Gutierrez, Howard-Grenville, \& Scully, 2010). This suggests that existing members of a particular community need to recognise (new) members as a participants, that is, membership must be negotiated with others (Wenger, 1998). Identification is viewed not as a state of being at a certain point in time or a binary variable; but as an ongoing process of 'becoming' (Ashforth et al., 2008; Ashforth, Schinoff, \& Rogers, 2016; Langley et al., 2013). Specifically, the study builds on work considering identification to involve elements of both stability and process (Gutierrez et al., 2010; Kreiner, Hollensbe, Sheep, Smith, \& Kataria, 2015), and as both a process and an outcome (Ashforth, Harrison, \& Sluss, 2014). Also, I acknowledge that identification occurs simultaneously and complementary at multiple levels and targets within organisations (Ashforth et al., 2016; Sluss et al., 2012).

As part of understanding and acting within the context of an organisation, newcomers seek to build a self-definition, which their social identity is integral to. Who one is, is thus related to one's sense of where one is and what is expected of others (Ashforth \& Mael, 1989). A transcendence between "who have I been", "who am I now" and "who I might become" (Ashforth et al., 2008) - the process of becoming - is obvious to address during socialisation (Ashforth et al., 2014). Organisational socialisation theory originates from Van Maanen and Schein work, who define socialisation as "the fashion in which an individual is taught and learns what behaviors and perspectives are customary and desirable within the work setting as well as what ones are not" (1979: 211-212). Socialisation too is considered a process (Ashforth et al., 2014; Langley et al., 2013), one which is continuously renewed through relations of persons, actions and the world in which they evolve (Lave \& Wenger, 1991). Further, I view socialisation as based on event time involving nonlinear events of experiences and eventually processes of sensemaking, as opposed to clock time, viewing socialisation as a linear adjustment phase during a specific time (Ashforth et al., 2014). Although identification has been connected to socialisation in earlier work, most recent research has been of quantitative character (Ashforth et al., 2014). In theoretical work, the relation between identification and socialisation is often just mentioned in passing (see Ashforth, Schinoff, and Rogers' (2016) exception to this). There is thus limited work considering both identification and socialisation, despite encouraging remarks by several scholars for decades, in particular for longitudinal, ethnographic studies (Ashforth et al., 2014; Ashforth \& Mael, 1989; Pratt, 1998; Sluss et al., 2012). Identification then, could be the "dark horse of the socialisation process" (Kammeyer-Mueller \& Wanberg, 2003, p. 950). Moreover, although it is recognised that it is through practices that we become members of a community such as a work team (Lave \& Wenger, 1991; Wenger, 1998), most emphasis has been put on the community, and not as much on the practices involved (Duguid, 2005), and thereby the actual work members engage in. Finally, little research has attempted to address identification and socialisation from a process perspective, leaving opportunities for future research (Ashforth et al., 2008; Langley et al., 2013).

\section{METHOD}

The study is based on a longitudinal ethnography of two teams from two knowledge-based organisations over a two-and-half-year stretch in two phases, amounting to fifteen months of fieldwork. The two Danish-located organisations are Vigus Energy Technologies A/S (Vigus) and the Scandinavian Infrastructure Consultancy (SIC) (both pseudonyms). Both teams experienced an on-going in-take of newcomers during the study, who were met by a learning-by- 
doing approach to socialisation. The data consisted of observations throughout the study, 55 formal and countless informal interviews, and archival documents. The two-phase longitudinal design allowed for reflection and validating of the first-phase emerging findings, including refinement of the coding and analytical work.

\section{FINDINGS}

\section{Newcomers' Socialisation Process}

At a glance, the two teams were very alike - dedicated, ambitious and highly skilled engineers working under pressures of deadlines, performance and high workload. An on-going dilemma was for newcomers to become more experienced, as the socialisation process was informal and somewhat random. In that sense, newcomers learned what they had to do "the hard way (laughs); trying, making it wrong and then trying again" (Madalina, newcomer, Vigus). This meant that newcomers had a hard time getting hands on work, as one exclaimed about his workload; "right now? 10 \%" (Antonio, newcomer, Vigus). In general, they "would have liked to have more work to do" (Anne, newcomer, SIC), but as Antonio from Vigus explained; "at the beginning it was like some small tasks and it was like, ok I'm already done with this, what can I do now? And nobody had an answer for that." Many newcomers, like Antonio, in effect became excluded from the team's tasks. Newcomers therefore engaged in 'identification work', behaviours that would make them feel part of the team and foster their identification. At the same time, existing team members engaged in what I call 'socialisation work', behaviours that would either hinder or foster newcomers' journey from peripheral towards full group membership. Socialisation work assisted (and in some cases halted) newcomers' socialisation process and experience of belonging. Further, based on the norms and values in the teams, members' negotiated acceptance mechanisms determined how newcomers' became considered as members of the team.

\section{Identification Work}

Newcomers engaged in identification work that was appreciated in the teams, specifically by figuring out what to do independently, working hard and by doing petty work.

\section{Figuring Out.}

To really be effective you have to be really good at making the most of the information you have at hand and not be too concerned having everything written out line by line, what you need to do, you have to run with what you have. (Jonathan, intermediate, Vigus)

Although it was not problem-free to figure out what do independently, it was something newcomers strived to do, as Lauren from SIC explained; "it's a challenge to know what I should do by myself and what should I ask about. Sometimes I actually spend time figuring things out by myself, which I really cannot figure out myself." While this might seem counterintuitive, newcomers at times remained passive and did not always ask for help when needed, because they did not want to bother and disturb the busy team mebers; it was a way of fitting in.

Working Hard. In both teams being busy signified being good, and working hard was a way 
of achieving that. Obviously reflected in hours worked, there was a general desire to do well, as Paul from Vigus said: "sometimes I am a bit frustrated because I want to do it well, and maybe I want to learn too fast, so I go home and spend a weekend with that." However, working hard was often hindered because team members did not pass on work to newcomers, either because they were not trusted with the work, or were not considered able to solve the task at hand.

Doing Petty Work. Despite newcomers sought to figure out what to do independently and were eager to work hard, however, oftentimes the lack of work newcomers had meant that some resolved to petty work, as Anne, a newcomer from SIC, for instance, said:

Often I say to my partner when I'm on my way, 'I don't want to go, I don't have anything to do'. But the days when I have work to do, I look forward to coming, and it actually doesn't matter if I have to sit and write minutes at a meeting or something else.

Anne was so eager to work that what for her as an engineer would be petty work, was better than the alternative. At times, petty work even involved looking occupied, illustrating what means some newcomers used not to bother others, as Kasper from SIC admitted:

"we (the newcomers) can't continue reading [product] regulations. I caught myself sometimes just having [the website] open, but I wasn't reading; I just sat there staring at it blindly."

\section{Socialisation Work}

As team members were responsible for socialising newcomers, a dilemma remained; it "depends whether you prioritise socialisation of newcomers" (Frederik, experienced, Vigus). I found that team members engaged in interrelated forms of behaviours that either hindered or fostered newcomers socialisation; me-working versus team-working, excluding versus embracing and detaching versus bonding.

Me-working versus Team-working. Some members engaged in me-working, such as working from home whenever possible to get work done without disturbances from less experienced colleagues. Others, in the interest of quickness and quality, simply had a hard time delegating work. Too, the highly specialised and knowledge-based work contributed to a somewhat lacking sense of common purpose that made members work independently. Me-working was more apparent in Vigus, strengthened by a weak emphasis on social bonding between members. In contrast, team-working flourished in Vigus, which involved members expressing positive distinctions about the team, delegating tasks and supporting each other. For example:

Even though we are both tired and exhausted and we want to finish our work, he is always welcome [to call me] and I'm always welcome to ask him, even if it's 2 o'clock in the morning. (Siya, experienced, SIC)

What was missing in the Vigus team was "some common ambitions, where we could all contribute" (Hans, experienced). To which extent members were able to engage in team-working behaviours was therefore both a result of organisation and members' incentive to do so. 
Excluding versus Embracing. A second way team members engaged in socialisation work was by excluding, or conversely, embracing newcomers. Excluding newcomers rested on team members not having enough time, because "working with people with little experience, to get them going and helping them; there's no time for that if someone needs your input on something you can do much faster than they can" (Frederik, experienced, Vigus). Others excluded newcomers because they were selective of whom they worked with, as one said:

Some [of us] are hard as nails, I think... If they find out that what someone did wasn't good, then they'll never use that person again. (Philip, experienced, SIC)

In general, experienced members found that their tasks were "difficult to pass on" (Hans, experienced, Vigus). In contrast, embracing newcomers included willingly investing and taking the time to sharing knowledge with them, creating a safe environment and viewing them as a resource. Members usually embraced newcomers, also because the team cultures emphasised helping newcomers, as Siya from SIC explained:

I know that if I help for one hour then I need to work 19 hours instead of 18, but I want to help him or her, because I know how it would be, if I had such a question.

\section{Detaching versus Bonding.}

The work is one thing, but if you don't have pleasure from the social interactions you have, it could but the most interesting job ever, but if your colleagues are really boring, or you hate your manager, you're not going to last very long. I think [the social aspect] is as important as the actual work. (Jonathan, intermediate, Vigus)

In this quote the significance of bonding is underlined as a central part of feeling part of the team, despite most members in Vigus experienced detaching. Lauren for instance felt; "I don't feel that much... There's nothing a lot apart from really professional", or as the experienced Frederik said; "the people are fine, we get along well, but we don't really talk with each other, we coordinate stuff". In comparison, team members at SIC were better at bonding and were "very attached to each other" (Siya, experienced), felt "lucky to have the group" (Sarah, intermediate), and that having a "cool environment, happy colleagues and positive atmosphere (...) is absolutely not a given it's like that, it's something that you should appreciate" (Philip, experienced).

\section{Acceptance Mechanisms}

The cultures of the two teams determined how new members were accepted as full team members through negotiated acceptance mechanisms. In that sense, the interaction between newcomers and experienced members triggered continuous identification work in alignment with existing members' socialisation work. I identified four implicit ways to be accepted by the team members; competence, initiative, paying the price and tenure. The key requirement in both teams was competence; "that's what fire people up here; to become so skilled that you make very few mistakes (Philip, experienced, SIC). Taking initiative was especially encouraged to newcomers in Vigus, and considered integral part of becoming a team member. 
As Jonathan, an intermediate explained, "it's really important to be very assertive and just call people or go up to their desk". A third way being accepted was by what Barker's (1999) labelled 'paying the price'; representing members willingness to do whatever it takes to be a team member. This included willingly working extra hours to finish the job on time, making an effort and having the right mentality, as Hans from Vigus stated; "others [from the team] might view it as a job, where we [the experienced] also see it as a hobby". The final way of being accepted by members was simply through tenure; by being a team member long enough to see new, and more junior members join the team. Generally, however, it took years for members not to feel or be considered by others as new anymore.

\section{DISCUSSION AND CONCLUSIONS}

In understanding how micro-processes of socialisation construct newcomers' identification, at least two explanations stand out as to why newcomer's identification became so dependent the collective socialisation processes. The first was the distance to management hierarchically, mentally and physically - which resulted in more responsibility put on the team members accompanied by the unobtrusive presence of peer-based control (Barker, 1993). The learning-by-doing approach to socialisation led to experiences where "nobody had an answer" and struggles with whom to rely on or ask for help. While uncomfortable and not satisfactory for newcomers, it was for experienced as well, who were "forced" to perform the roles of socialisation agents, some involuntarily. In addition, the hierarchical vacuum the distance to management also left meant that when members were forced into such a role, they might hinder instead of foster the newcomers' socialisation process, for example, by not bothering about newcomers or assuming that others would take on such responsibility. The second reason is related to the power of the teams' cultures. Created by the team members, newcomers had to resonate with the team's sharedness and buy into the team culture in the negotiation of membership (Wenger, 1998; Fine \& Hallett, 2014). In becoming less peripheral, newcomers' had to be accepted according the team members' acceptance mechanisms. Surely, the acceptance mechanisms reflected that in becoming experienced, newcomers had to become more like them (Van Maanen \& Schein, 1979); to possess the same qualities, such as having the same mentality by viewing the job as a hobby or portraying constant busyness. Overall, newcomers' socialisation experiences proved to be very reliant on key socialisation agents (Feldman, 1994; Jones, 1986). While these mechanisms emerged within the teams precisely because socialisation happened within and by the teams, they were mostly unspoken and implicit. A downside to this was that there was only so much a newcomer could do to be socialised and experience identification, because they were dependent on the team members in socialising them too. The newcomers' identification work and existing members' socialisation work were thus highly interrelated processes, which would trigger each other. In a sense, experienced members then partly acted as "gatekeepers" to newcomers' full participation and membership in the team. The study portrays how socialisation of newcomers in two teams unfolded informally through microprocesses of socialisation. Overall, the importance of fellow team members as socialisation agents seems greater than today given credit for within socialisation theory, especially in autonomous and participatory work designs, such as the ones studied here. While newcomers must work their way in becoming part of a team, existing team members must work them in too.

\section{REFERENCES AVAILABLE FROM THE AUTHOR}

